\title{
A model of phytoplankton production in the marginal sea-ice zone of the Barents Sea.
}

\author{
DAG SLAGSTAD +
}

Keywords: modeling, phytoplankton, ecosystem, simulation.

The primary production in the Barents Sea must be high since it can sustain large stocks of fish. The factors controlling the primary production is not well understood. This paper takes the physical conditions (as far as we know them) in some of the ice-covered areas of the Barents Sea as an input to a plankton model. Simulations with different combinations of vertical turbulence and ice cover indicate that the ice concentration is important in shallow areas with strong tidal mixing, whereas the date of the start of melting of the ice and the resulting stabilization of the water column are more important in deeper parts of the Arctic waters. Where the Atlantic waters flow towards the ice border, the primary production starts early in the spring. High phytoplankton concentration is always found in this area. Study of the model results shows that the following mechanism could be responsible for the elevated biomass: turbulent Atlantic water, relatively rich in nutrients, stabilizes when meeting the ice or brackish water from the melting process and allows a high growth rate as soon as there is enough light early in the spring. High production may last for $2-3$ months in this area.

\section{Introduction}

A model study of a marine ecosystem is always based on some knowledge or assumption about the most important physical parameters affecting the system. If, for instance, migration and population dynamics of fish are to be modeled, physical parameters such as temperature, salinity, advection and day-length are of great importance whereas vertical mixing is of minor interest. On the other hand, if production of phytoplankton is to be modeled, the salinity as such is of minor interest, but its effect on vertical mixing is of major interest.

In the Barents Sea the physical conditions may be very much different from one area to another even small distances apart. The main reason for these differences is the ice which reduces the influence of the atmosphere on the water-masses compared with ice-free areas. Waters from different origins also contribute to change the physical conditions depending on geographical position. Large fisheries in this area indicate that we have high primary and secondary production, but the mechanisms controlling the production are less known.

In this paper we will use a phytoplankton model which is similar to most of the models found in the literature, but the model will be driven by the physical conditions we find in the area of the marginal ice-zone of the Barents Sea. Hydrographical and biological data from the area are found in Rey and Loeng (1984) and Ellertsen et al. (1981).

Received 28 November 1984.

† This paper was presented at the 18th European Marine Biology Symposium, Oslo, August 1983 and will appear in Marine Biology of the Polar Regions and Effects of Stress on Marine Organisms, edited by J. S. Gray and M. E. Christianson, John Wiley \& Sons (1985),
664 pp.

$\ddagger$ The Foundation of Scientific and Industrial Research (SINTEF), Division of Automatic Control, The Norwegian Institute of Technology, N-7034 Trondheim-NTH, Norway. 


\section{The physical conditions}

Figure 1 shows a map of the Barents Sea with 100 and 200 metre isolines. The filled arrows show the direction of flow of the warm, Atlantic water whereas the broken arrows show the flow direction of the cold, Arctic water (from Loeng 1979, Tantsiura 1959). The ice-border may vary much from year to year and from season to season, but here we assume that it follows the hatched area during the whole simulation period.

Three examples will be shown which take the physical conditions from three selected situations as driving force for the biological model. These examples (as numbered on the figure) are:

(1) The Svalbard Bank which is characterized by depths less than 100 metres. The water column is usually well mixed from bottom to surface (Loeng, personal communication).

(2) Deeper parts of the Barents Sea, north of the Polar Front where the tidal mixing is low. When the ice starts to melt in the spring, the water column is stabilized.

(3) Section from Atlantic water through the Polar Front and into the Arctic water.

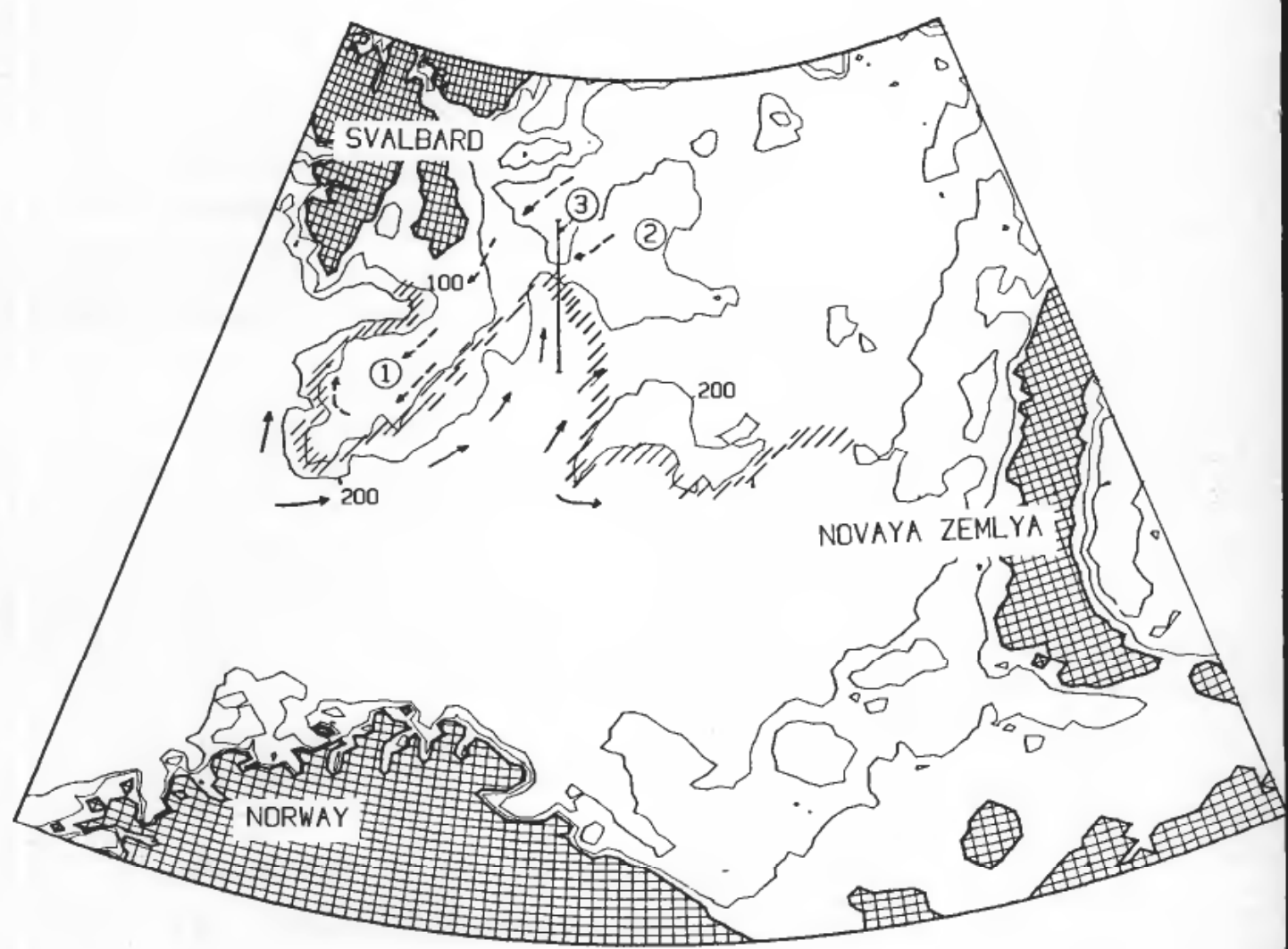

Figure 1. Map of the Barents Sea showing depth contours at 100 and 200 metres. The hatched area indicates the assumed position of the ice border during the simulation period. 


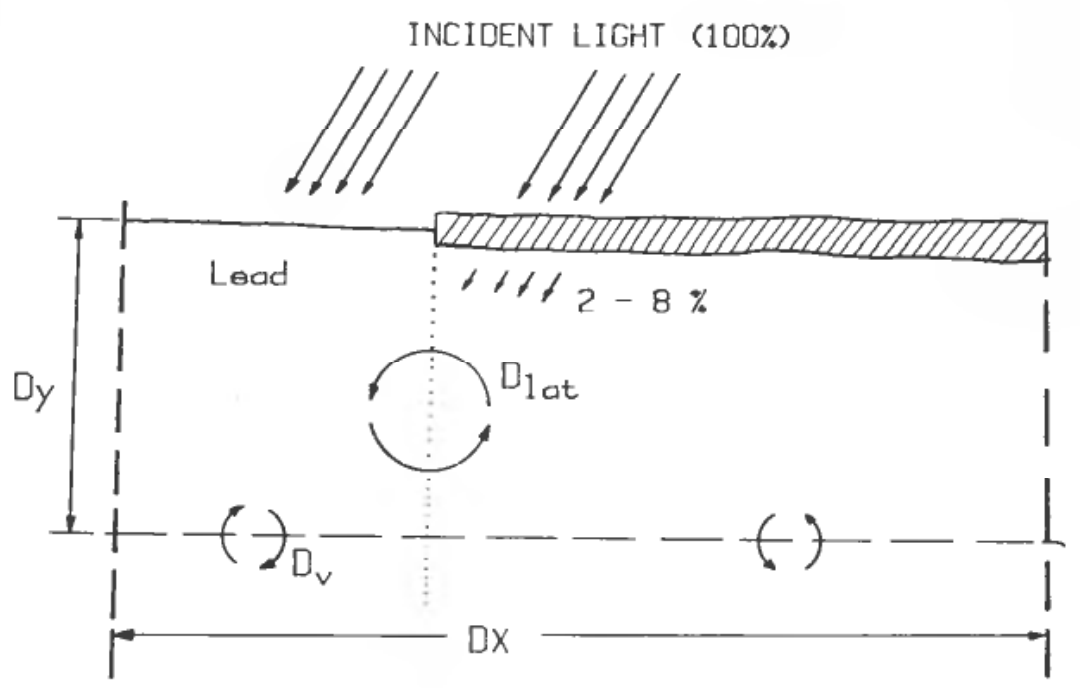

Figure 2. The special 'lead model'.

The first two examples will illustrate the effect of vertical mixing on the phytoplankton dynamics in ice-covered areas whereas the third one will take into account the horizontal transport of phytoplankton and nutrients. As we shall see, the horizontal transport has a profound effect on the primary production.

When calculating growth of phytoplankton, light is an important parameter. In ice-covered areas the light that the algal cells receive is difficult to estimate. In leads $100 \%$ of the incident sunlight is available at the sea surface whereas underneath the ice only a few per cent is left for growth of phytoplankton. The transport of ice is strongly affected by the wind whereas the water transport, in addition, is affected by other physical parameters in the sea. As a result, the water and its plankton receive light of constantly changing intensity. The amount of chlorophyll necessary for collecting sufficient energy for growth will vary in a similar way. The algal cell is not able to adapt fast enough to respond to these light variations, but rather responds to some average intensity depending on the ice concentration and its ability to transmit light. To build a model with a resolution high enough to account for the light variation is impossible from a data point of view, nor is it necessary.

The model we construct here is two-dimensional, one horizontal and the other vertical. We assume the leads in one area (on the order of a few kilometres) are collected in one part of the area whereas the ice floes are collected in the other part, in shown in Fig. 2.

A large horizontal mixing coefficient $\left(D_{\text {lat }}\right)$ is assumed such that the water masses in the lead and under the ice may be regarded as completely mixed. This model is in close interaction with a more general phytoplankton model which calculates transport, mixing and growth for ice-free areas.

\section{The phytoplankton model}

\subsection{Formulation of the equations}

The structure of the ecological model used in the examples shown in the next section is shown in Fig. 3. The model system contains submodels for zooplankton 


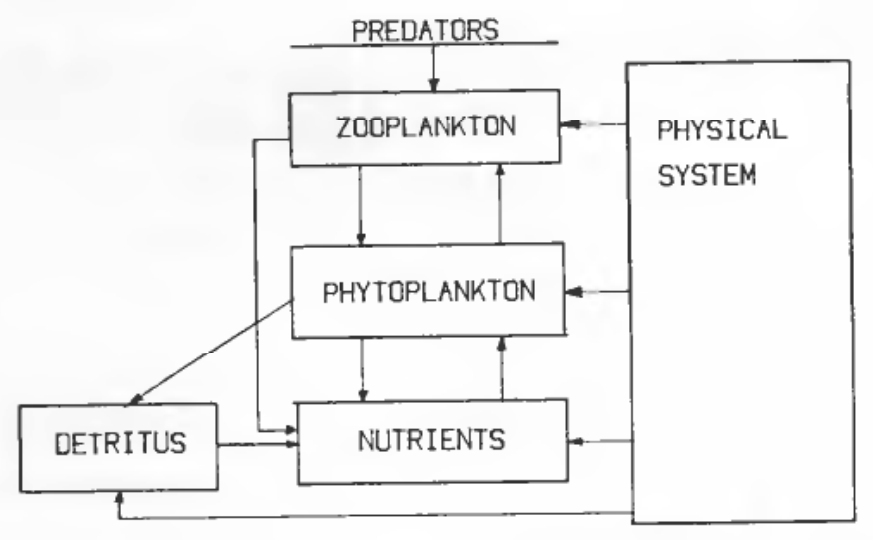

Figure 3. Block diagram of the plankton model.

and phytoplankton and the physical transport and mixing. The physical parameters such as advection velocity, mixing, temperature and light are specified. Here, we will concentrate on the phytoplankton submodel.

Growth of phytoplankton depends on a great number of cellular characteristics, besides the environmental variables such as light, temperature and nutrients. Chlorophyll content is one of the most important cellular characteristics in a highly variable light regime such as we have in the ice-covered areas. In Slagstad (1982) and references therein, a model of phytoplankton growth using chlorophyll content as a property controlling the affect of light on the growth rate is described. Only a short description is given here.

Most data describing the relationship between chlorophyll, light intensity and the growth rate of the algal cells use the light intensity at which the cells are adapted $I_{0}$, instead of chlorophyll content as a measure of adaptation. When implementing a mathematical model on a computer, we usually have to discretize the water column in sheets or layers of a certain depth. We assume that each layer is well mixed and has the same $I_{0}$. After entering a certain layer the algal cells are trying to adapt towards $I_{0}$ which is specific for the light conditions in this layer. The equation describing the growth, transport and turbulent mixing of phytoplankton is

$$
\frac{\partial P}{\partial t}=-u \frac{\partial P}{\partial x}-\left(w+w_{p}\right) \frac{\partial P}{\partial z}+\frac{\partial}{\partial x}\left(D_{h} \frac{\partial P}{\partial x}\right)+\frac{\partial}{\partial z}\left(D_{z} \frac{\partial P}{\partial z}\right)+f_{\text {biol }}
$$

and the rate of adaptation in layer no. $i$ is

$$
\frac{d I_{0}}{d t}=v_{I_{0}}\left(I_{0 W}^{i}, I_{0}^{i}, T\right)
$$

Where $z$ is the depth coordinate, $x$ is the horizontal coordinate and $t$ is time. The first and third terms on the r.h.s. of equation (1) represent horizontal transport and horizontal turbulent mixing, respectively; whereas the second and the fourth terms represent vertical transport and vertical turbulent mixing. $P(t, z)$ is the concentration of phytoplankton (in nitrogen units) at time $t$ and depth $z . I_{0}^{i}$ is the average adaptation light intensity of cells occupying layer no. $i$ in the water column, and $I_{0 w}^{i}$ is the light intensity towards which the cells adapt after arriving at layer no. i. $v_{I 0}$ is 
the rate of adaptation and $T$ is temperature. The biological term, $f_{\text {biol }}$, describes how respiration, light, nutrients and grazing affect the phytoplankton production.

$$
f_{\text {biol }}=\mu_{\max }^{E} f_{1}\left(I_{z}, I_{0}\right) G_{N} \dot{P}-\phi_{r} P-q_{I}(P)
$$

The first term on the r.h.s. of the equation represents the phytoplankton growth term, and the second term represents the respiration and mortality of the phytoplankton. The last term gives the effect of the grazing pressure from the zooplankton.

$\mu_{\max }^{E}$ is the cell division rate at optimum light and at a given temperature (the superscript ' $E$ ' means maximum division rate when using Eppley's (1972) equation). The relationship between the rate of photosynthesis and light intensity, $f_{1}\left(I_{z}, I_{0}\right)$ is described in Slagstad (1982). The effect of the concentration of nitrogen is assumed to follow the well-known Michaelis-Menten expression which gives the ratio of the actual growth rate to the maximum growth rate.

$$
G^{N}=\frac{N}{k_{N}+N}
$$

where $k_{N}$ is the half saturation constant and $N$ is the concentration of nitrogen. The sinking rate of phytoplankton $w_{p}$ is taken to be a function of nitrogen in the surrounding water masses.

Growth of phytoplankton will remove nutrients from the water. Since we have assumed that nitrogen is the only nutrient to be limiting, we need to take into account the transportation, regeneration and uptake of nitrogen. Regeneration takes place partly through excretion from zooplankton and partly through bacterial decomposition of detritus. The equations describing the dynamics of nitrogen and detritus are:

Nitrogen

$$
\begin{aligned}
\frac{\partial N}{\partial t}= & -u \frac{\partial N}{\partial x}-w \frac{\partial N}{\partial x}+\frac{\partial}{\partial x}\left(D_{h} \frac{\partial N}{\partial x}\right)+\frac{\partial}{\partial z}\left(D_{z} \frac{\partial N}{\partial z}\right) \\
& -\mu_{\max }^{E} f_{1}\left(I_{z}\right) G_{N} P+\phi_{d} D+E^{z}
\end{aligned}
$$

Detritus

$$
\frac{\partial D}{\partial t}=-u \frac{\partial D}{\partial x}-\left(w+w_{d}\right)+\frac{\partial D}{\partial z}+\frac{\partial}{\partial x} D_{h} \frac{\partial D}{\partial x}+\frac{\partial}{\partial z} D_{z} \frac{\partial D}{\partial z}+\phi_{r} P-\phi_{d} D
$$

The four first terms of the r.h.s. of the equations represent the horizontal and vertical transport and horizontal and vertical turbulent mixing, respectively. Growth of phytoplankton is accompanied by a decrease in concentration of nutrients which is accounted for by the fifth term in eqn. (5). The sixth and the seventh terms of eqn. (5) represent the regeneration of nutrients from detritus and the zooplankton, respectively. Detritus is assumed to originate from dead phytoplankton, term six in eqn. (6).

\subsection{Biological and physical parameters}

We always start our simulation runs with a homogeneous distribution of the limiting nutrient (nitrate) equal $10 \mu M N$. The vertical water column is divided into layers of depth 5 metres. Each layer is assumed to be homogeneous and the vertical 
mixing coefficient describes the turbulent mixing between the layers. The extinction coefficient is taken equal to $0.04 \mathrm{~m}^{-1}$ for pure oceanic water. Temperature is taken equal to $3.0^{\circ} \mathrm{C}$ in Atlantic waters and $-1.8^{\circ} \mathrm{C}$ in Arctic waters. Light is calculated from the theoretical height of the sun with $40 \%$ damping through clouds. The phytoplankton model is coupled to a zooplankton model described by Slagstad (1981), which exerts a certain grazing pressure upon the algal cells.

\begin{tabular}{|c|c|c|c|}
\hline $\begin{array}{c}\text { Parameter } \\
\text { name }\end{array}$ & Units & Value & Meaning \\
\hline$k_{N}$ & $\mu \mathrm{M} \mathrm{N}$ & $1 \cdot 0$ & Half-saturation constant for nitrate \\
\hline$\phi_{r}$ & $\mathrm{~h}^{-1}$ & 0.002 & Respiration rate of phytoplankton \\
\hline$\phi$ & $h^{-1}$ & 0.043 & $\begin{array}{l}\text { Rate of bacterial decomposition of } \\
\text { detritus into nutrients }\end{array}$ \\
\hline$w_{d}$ & $\mathrm{mh}^{-1}$ & 0.02 & Sinking rate of detritus \\
\hline$w_{0}$ & $\mathrm{mh}^{-1}$ & 0.08 & $\begin{array}{l}\text { Sinking rate of phytoplankton when } \\
\text { the nutrients are depleted }\end{array}$ \\
\hline$w_{00}$ & $\mathrm{mh}^{-1}$ & 0.02 & $\begin{array}{l}\text { Sinking rate of phytoplankton at high } \\
\text { nutrient level }\end{array}$ \\
\hline
\end{tabular}

Parameters used in the simulation runs.

\section{Simulation results}

\subsection{The primary production is sensitive to ice concentration when the mixing is deep}

In the shallow Svalbard Bank area the tidal currents keep the water column well mixed throughout the spring and the summer. The production of phytoplankton depends both on the depth of the water column and the concentration of ice. Figure 4 shows the concentration of chlorophyll in the water column as a function of time for different concentrations of ice. The upper and the lower figures show how the model simulates the production when the water column depth is 50 and 100 metres, respectively. When there is no ice, the production starts in the second half of March, not much affected by the depth of mixing. The spring bloom will last for several weeks under conditions which are dominating in this case. This is opposed to what is usually found at more southern latitudes. The reason for this is the low temperature $\left(-1.8^{\circ} \mathrm{C}\right)$ which slows down the growth rate. But, more important, the grazers will also grow slowly and thereby delay the grazing pressure from the new generation. If the ice concentration increases, the production start is delayed and the maximum concentration of chlorophyll at the date of culmination of the primary production is lowered. For a depth of mixing of 100 metres and ice concentration more than $60 \%$ there is hardly any primary production.

In this area, the ice conditions may vary much from year to year. As the production depends so much on the ice cover, corresponding fluctuations in primary production may be expected from year to year.

\subsection{Low mixing allows early production under the ice}

Over the deeper parts of the Barents Sea, north of the Polar Front, the mixing process is not dominated by the tidal currents, but rather by the freezing and melting of ice. In early spring, before melting takes place, we assume that the water 

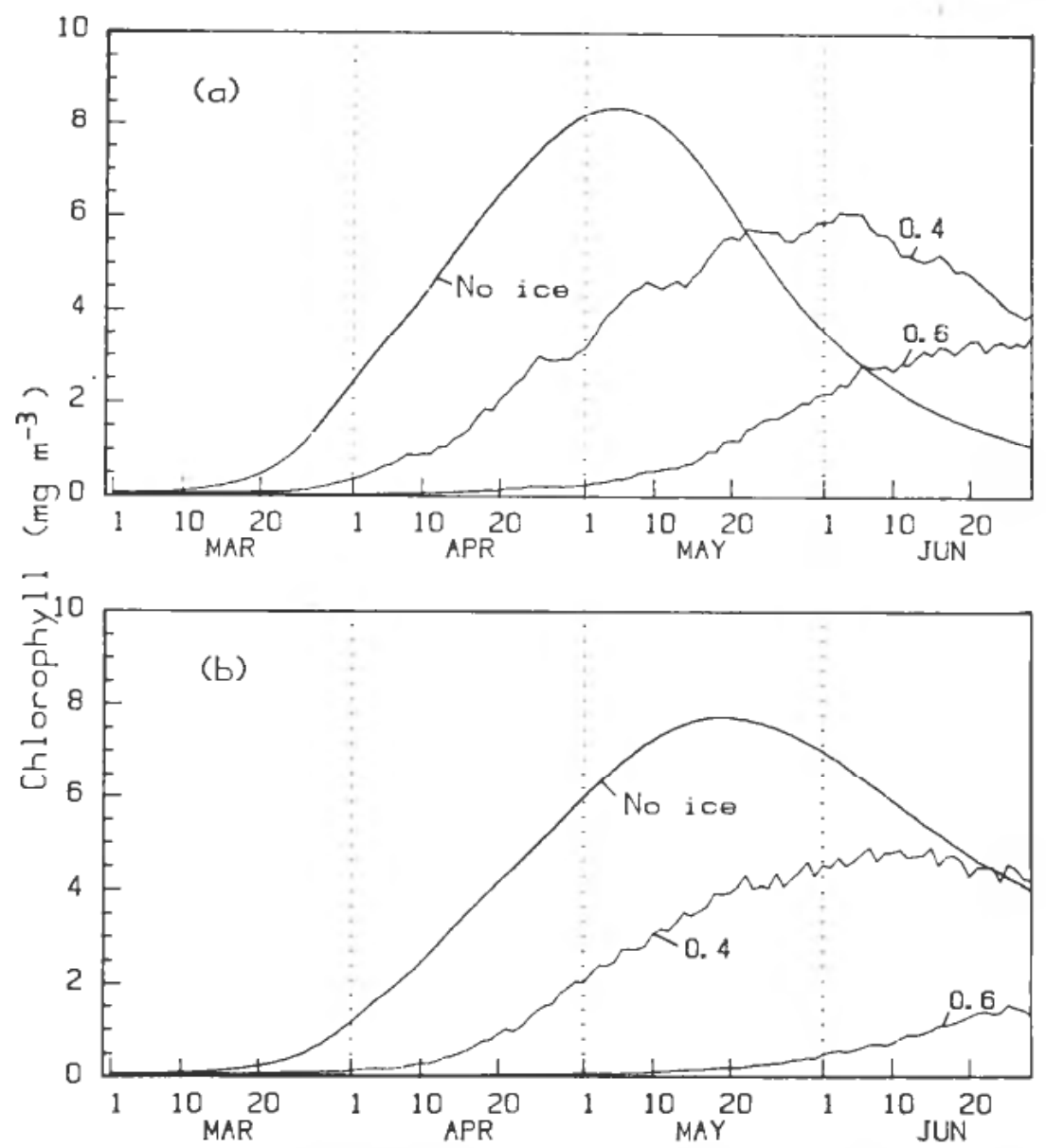

Figure 4. Concentration of chlorophyll as a function of time for 60,40 and $0 \%$ ice cover and water column depth $50 \mathrm{~m}(a)$ and $100 \mathrm{~m}(b)$.

column is mixed down to 100 metres. After the melting of ice starts, water of low salinity water is released and the water column stabilizes. We assume that melting start May 7 th and that $4 \%$ of the surface light is transmitted through the ice.

Figure 5 shows the chlorophyll concentration at the surface as a function of time for different ice concentrations. When the ice concentration is low, the production may take place before the water column is stabilized. Usually, however, the ice concentration is high in this period and the production starts after the water column has stabilized. Since we have a very strongly pycnocline which inhibits nutrients entering the surface area, the chlorophyll content becomes low. Below the pycnocline, however, the phytoplankton concentration is high.

We note that even if $100 \%$ of the surface is covered by ice, the assumed $4 \%$ transmission coefficient of light through the ice is enough to cause a small bloom in the first days of June.

\subsection{Section from Atlantic water into the Arctic water}

The position of the section is shown in Fig. 1. On basis of the data from Ellertsen et al. (1981) and Rey and Loeng (1985), a vertical cut along the section showing 


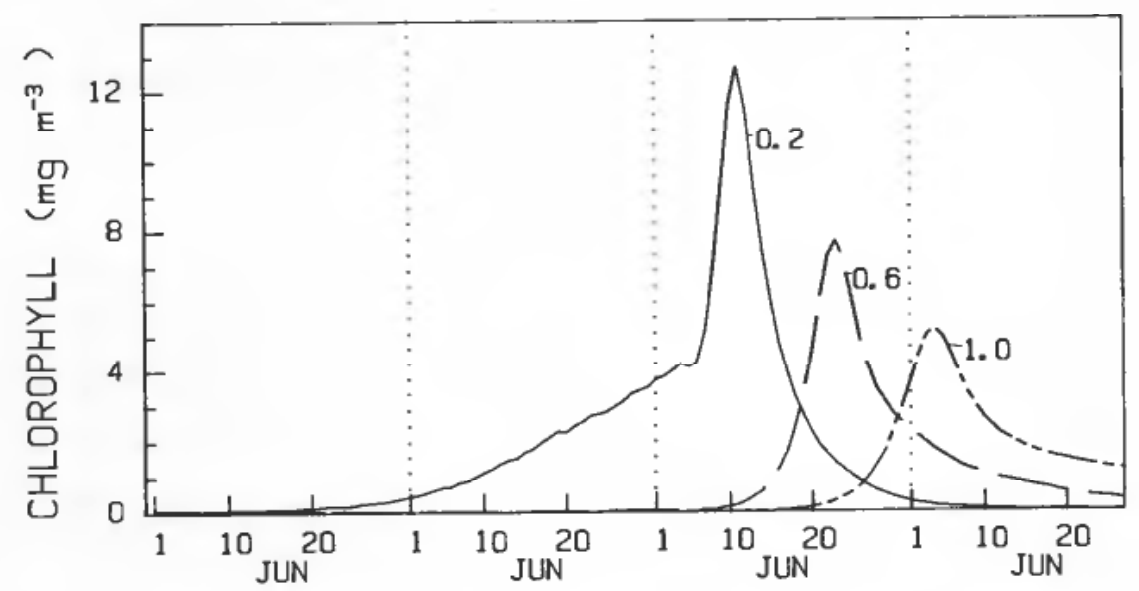

Figure 5. Concentration of chlorophyll as a function of time for 60,40 , and $0 \%$ ice cover.

the direction of flow and the typical watermasses is constructed in Fig. 6. The advection velocity is put equal to $4 \mathrm{~cm} \mathrm{~s}^{-1}$. The pycnocline is placed at a depth of 25 metres at the boundary between Atlantic water and melt water, and decreases linearly to a depth of 10 metres at the ice border. Usually, the ice border retreats at this time of the year, but in order to illustrate the effect of melting ice on the phytoplankton, we assume this border to be at a fixed position during simulation.

A long part of the Atlantic water flows into the area from south and west. Although the water temperature is several degrees above the freezing point in a 30-400 metre water column when entering the area, ice is formed during the winter. This is probably caused by ice from more northern areas which, driven by winds, meets the warm Atlantic water and melts. During the melting process, fresh water is released and a thin layer of brackish water is formed. A pycnocline divides the warmer Atlantic water from the cooler, brackish water and the transport of heat to the surface water is stopped. Now, freezing can take place and new ice can be formed. Since the ice is easily transported by the wind, brackish water is usually found between the pure Atlantic water and the ice border.

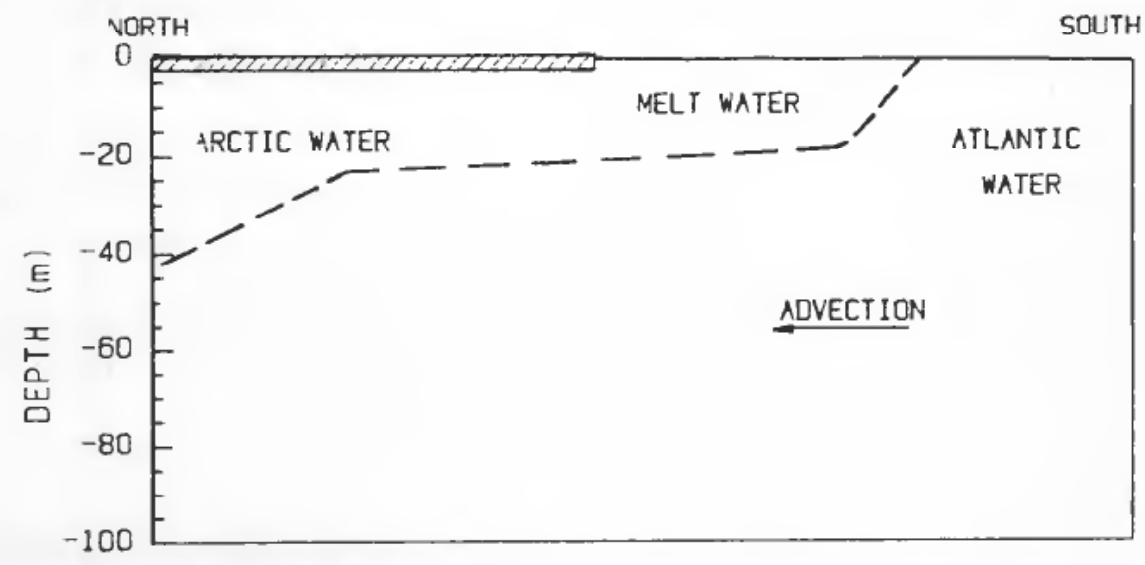

Figure 6. Principle model of the physical system at the ice border. 

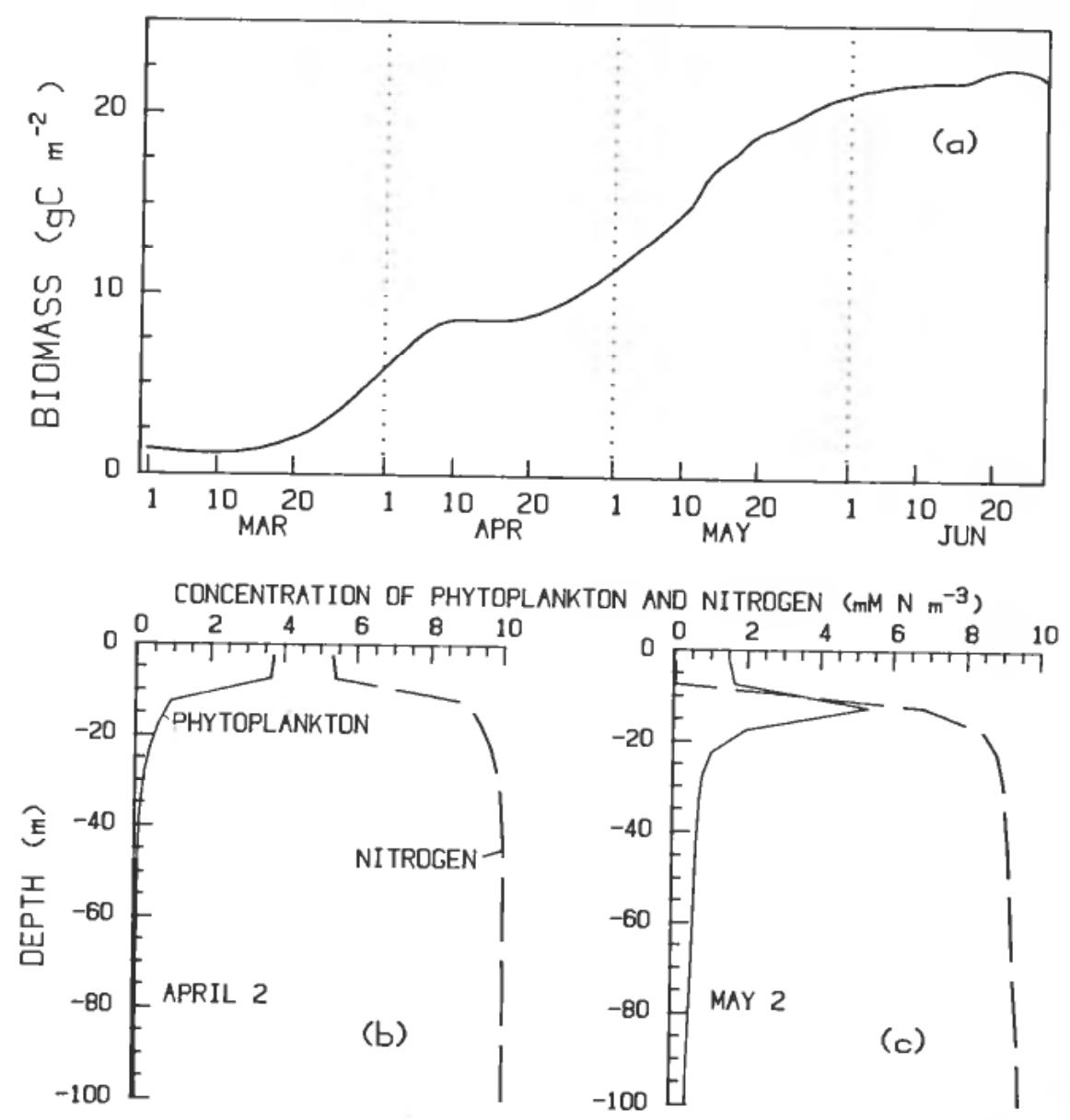

Figure 7. (a) Depth integrated biomass of phytoplankton at the front of the ice border as a function of time. $(b)$ and $(c)$ Vertical distribution of chlorophyll at two selected dates.

When the illumination increases during the spring, the growth of phytoplankton can take place. At the end of March a phytoplankton bloom takes place near the surface. As this surface water becomes exhausted of nutrients, the production becomes very low until the concentration of phytoplankton at the surface is reduced by grazing and sinking. When this happens, more light penetrates to the water under the pycnocline and the production starts again. A time series plot of the depth integrated biomass of phytoplankton at the front of the ice border is shown in Fig. $7(a)$. We observe that there is an exponential increase in the biomass in the second half of March and the first week of April, an increase which corresponds to production in the surface waters (See Fig. 7(b)). After a stagnation period a new exponential phase is seen which corresponds to production below the pycnocline (See Fig. 7(c)).

Typical salinity, temperature and chlorophyll distributions are shown by Rey and Loeng (1985). On basis of these data and from Ellertsen et al. (1981) a typical chlorophyll distribution in front of the ice border during the spring is constructed in Fig. 8 . 


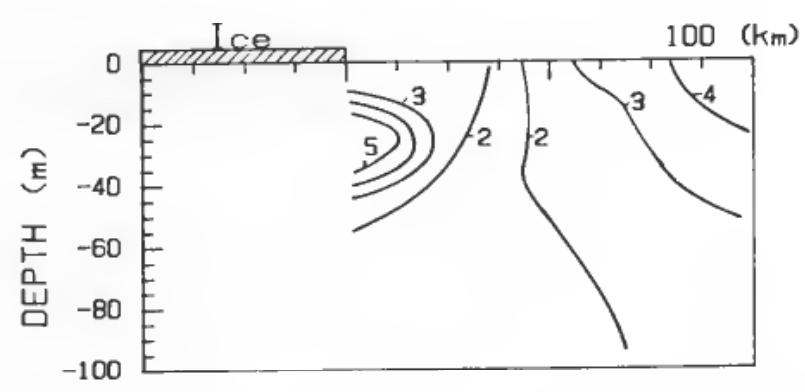

Figure 8. Typical chlorophyll distribution found south of the ice border in May/June.
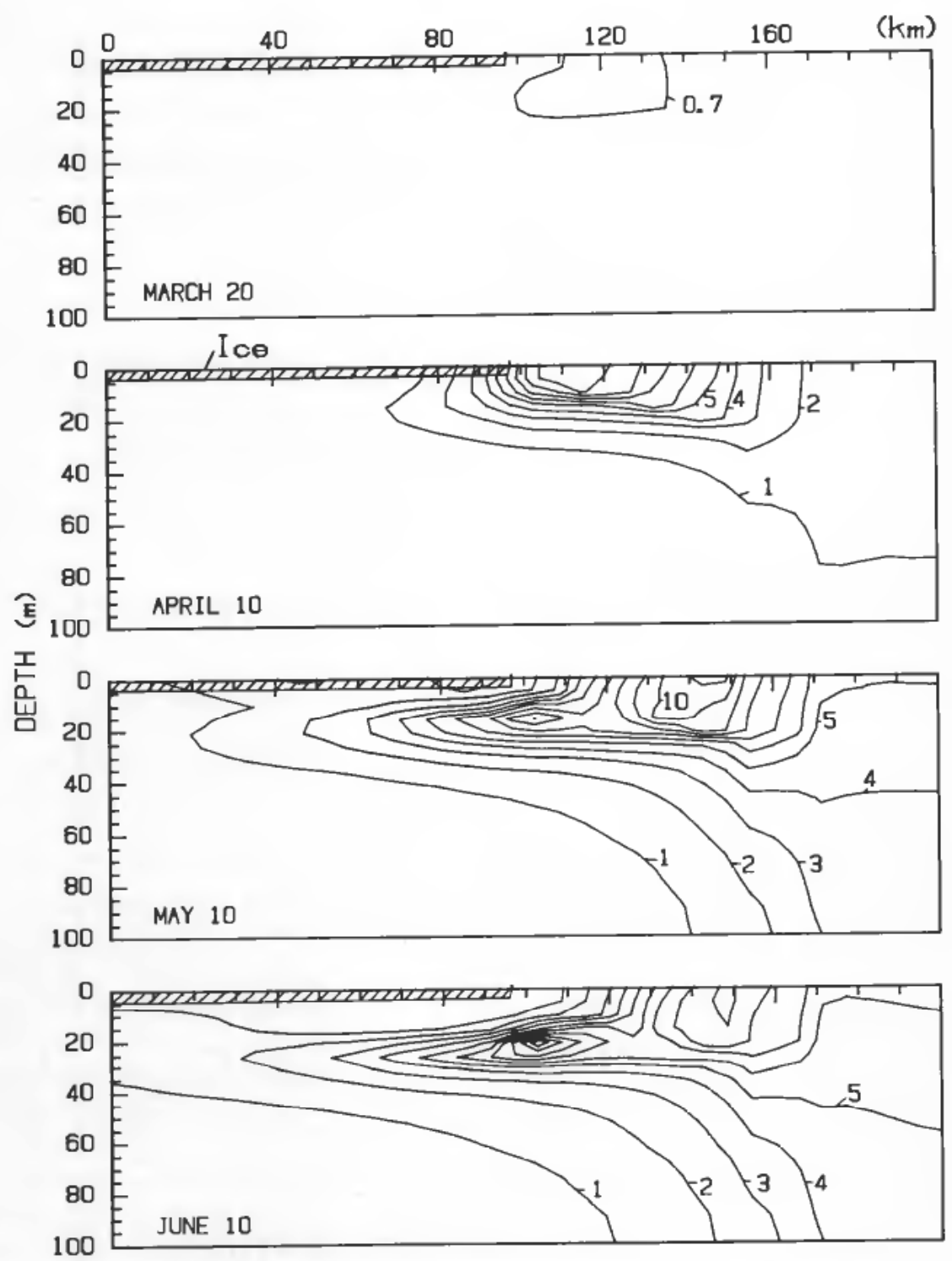

Figure 9. Simulated chlorophyll distribution $\left(\mathrm{mg} \mathrm{m}^{-3}\right)$ during the spring. 
A chlorophyll maximum is usually found near the ice at a depth of 20-30 metres. The nutrients are depleted near the surface. Further south, in the mixed Atlantic water, the chlorophyll concentration is about $2-4 \mathrm{mg} \mathrm{m}^{-3}$ and the concentration of nutrients high.

Simulated chlorophyll distribution during the spring is shown in Fig. 9. The production starts as mentioned in the second half of March in the meltwater south of the ice border. When nutrients are depleted in the surface water, the production shifts to a deeper level below the pycnocline. The Atlantic water, rich in nutrients, flows continuously towards the ice border and sustains a high production for a long period. The chlorophyll maximum produced below the pycnocline in front of the ice border is transported northwards, under the ice.

The chlorophyll concentration in the Atlantic water increases slowly because the depth of mixing is more than 100 metres. In the first half of May this concentration has reached $4 \mathrm{mg} \mathrm{chl} \mathrm{m}^{-3}$. Because self-shading now takes place, there is not much increase in this concentration until a thermocline is formed in the Atlantic water and a bloom takes place.

Simulated distribution of nutrients (nitrogen) is shown in Fig. 10. We observe that the nutrients are depleted in front of the ice border as early as the first days of April. In May the northward transport has caused a drop in the nutrient concentration under the ice without any significant production in this area. In mid-June a
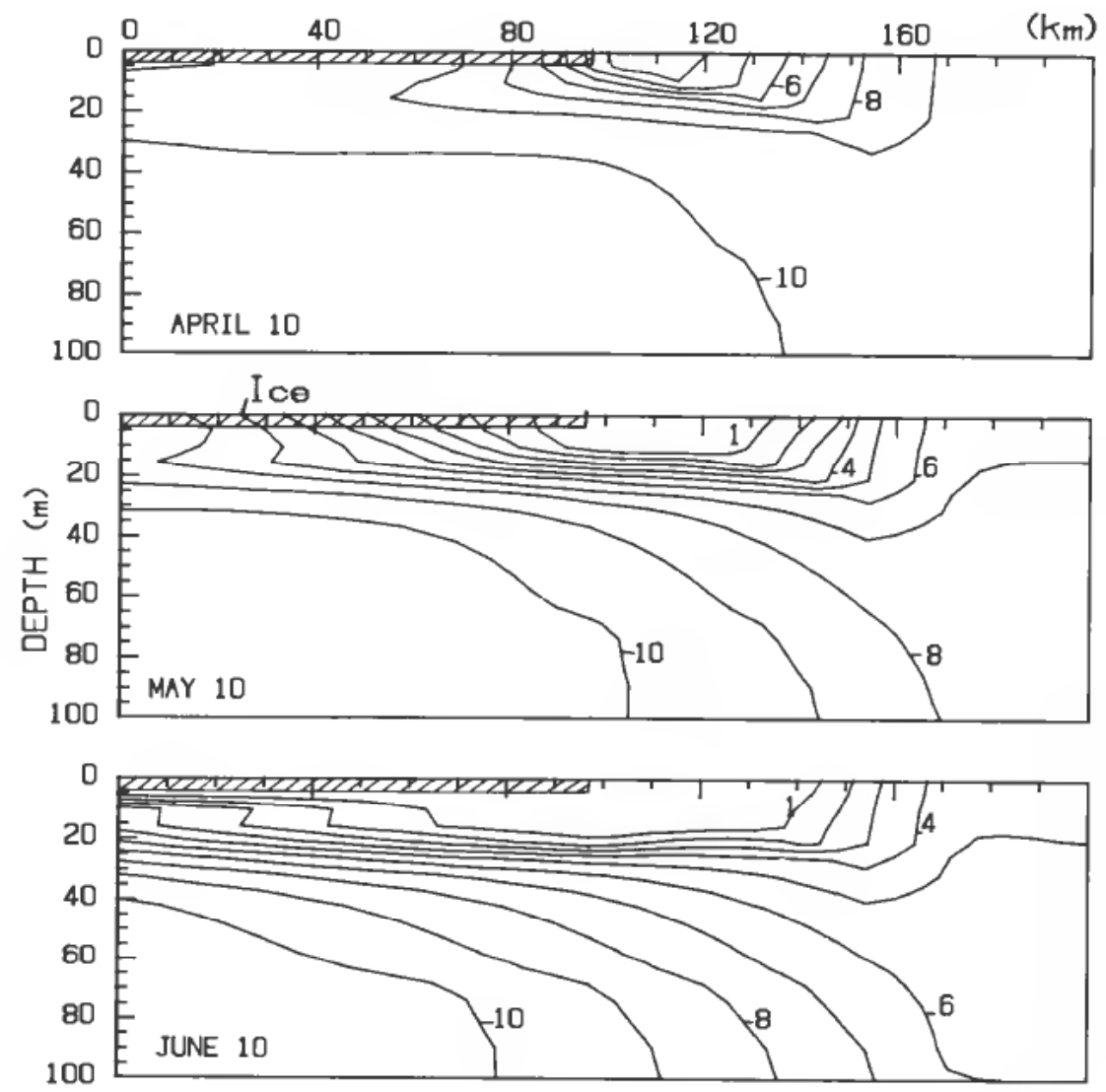

Figure 10. Simulated distribution of nitrogen $(\mu \mathrm{M})$ during the spring. 
high nutrient concentration is found below 20 metres under the ice. As the light intensity is not sufficient to allow any production, the algal cells have to wait for the ice to melt or drift away. Therefore, a bloom of phytoplankton is always found below the pycnocline in front of the ice border as it retreats during the summer.

\section{Discussion}

The first simulation examples indicated that the ice concentration had a pronounced effect on primary production when the water column was mixed down to 50-100 metres. In contrast, a stable water column could have relatively high production even with dense ice cover.

Zenkevitch (1983) indicated that areas along the Polar Front had higher bottom and plankton biomass than other areas. His explanation was that Atlantic waters which cool and sink at the Polar Front give rise to upwelling of Arctic water and thereby a supply of nutrients. The simulation results show that another mechanism may contribute significantly to elevated biomass in this region. The ice border is on the average situated near the Polar Front. As the Atlantic water, relatively rich in nutrient meets the ice, it stabilizes and produces a bloom of phytoplankton which may last for three months. High concentration of phytoplankton is often followed by high grazing and thereby high production of faecal pellets, which again supply the bottom fauna with energy.

\section{ACKNOWLEDGMENTS}

This work has been supported by The Norwegian Research Council and by The Research Programme OCEAN-BIO MODELS (HAVBIOMODELLER).

\section{REFERENCES}

Ellertsen, B., Loeng, H., Rey, F., and Tuelmeland, S. (1981). The feeding conditions of capelin during summer. Field observations in 1979 and 1980. Fisken Hav., 1-68. (in Norwegian).

EPPLEY, R. W. (1972). Temperature and phytoplankton growth in the sea. Fish. Bull., 70, 1063-1085.

LOENG, H. (1979). A review of the sea ice conditions of the Barents Sea and the area west of Spitsbergen. Fisken Hav., 29-75. (in Norwegian).

REY, F. and LOENG, H. (1985). The influence of the hydrographical conditions on the development of phytoplankton in the Barents Sea. In Marine Biology of the Polar Regions and Effects of Stress on Marine Organisms (Proceedings of the Eighteenth Marine Biology Symposium, held in Oslo, August 1983), edited by J. S. Gray and M. E. Christianson (Chichester: John Wiley \& Sons).

SLAGSTAD, D. (1982). A model of phytoplankton growth-effect of vertical mixing and adaptation to light. Modeling, Identification and Control, 3, 111-130.

SLAGSTAD, D. (1981). Modeling and simulation of physiology and population dynamics of copepods. Effects of physical and biological parameters. Modeling, Identification and Control, 2, 119-162.

Tantsiura, A. I. (1959). About the currents in the Barents Sea. Trudy polyar, naucho-issled. Inst. morsk. ryb. Khoz. Okeanogr., 11, 35-53. (in Russian)

Zenkevitch, L. (1963). The Biology of the Seas of the U.S.S.R. (London: George Allen and Unwin Ltd.) 